\title{
Performance Measurement and Management: What is Next?
}

\author{
PAOLO TATICCHI $\S$, FLAVIO TONELLI *, MOHAMED SAMEH $\S$, MARCO BOTARELLI \\ $\S$ Department of Industrial Engineering \\ University of Perugia \\ Via Duranti 17, Perugia
}

ITALY

* Department of Production Engineering, Thermo-energetic and Mathematical Models

University of Genoa

Via All'Opera Pia 15, Genoa

ITALY

paolo.taticchi@unipg.it

\begin{abstract}
The paper reviews the literature in the field of performance measurement and management (PMM) for small and medium enterprises (SMEs) and large companies. The methodology adopted for reviewing the literature relies on the citation/co-citation analysis of research on PMM and on the analysis of the frameworks/models developed in the last twenty years both for large and SMEs. The evolution of the research field is discussed and future areas of research are identified. The results of the literature review carried out reveal a certain maturity of the literature related to large companies and a significant lack of PMM literature for SMEs.
\end{abstract}

Key-Words: - Performance Measurement, Performance Management, SMEs, literature review, research agenda.

\section{Introduction}

Every company attempts to organize its activities in the most effective way [1]. As a consequence of that, interest on Performance Measurement and Management (PMM) has notably increased in the last twenty years. Particularly, it is important to note the evolution of focusing performance from a financial perspective to a non-financial perspective [2]. Since the middle of ' 80 s, companies emphasized the growing need of controlling production business processes. Companies have understood that for competing in continuously changing environments, it is necessary to monitor and understand firm performances. Measurement has been recognized as a crucial element to improve business performance [3]. A performance measurement and management system (PMS) is a balanced and dynamic system that enables support of decision-making processes by gathering, elaborating and analyzing information [4]. The concept of "balance" refers to the need of using different measures and perspectives that tied together give an holistic view of the organization [5].The concept of "dynamicity" refers instead to the need of developing a system that continuously monitors the internal and external context and reviews objectives and priorities [6]. An increasing competitive environment, the proneness of growing in dimension, the evolution of quality concept [7], the increased focus on continuous improvement and the significant developments in information and communication technologies [8] are the most important changes in recent years that have created a favorable context for the implementation of PMSs in SMEs, particularly in the manufacturing sector [9]. Although extensive research has been carried out to investigate the needs and characteristics of PMSs in large organizations, there is a distinct lack of published research on issues related to SMEs [10]. However, from the literature available it is possible to collect information regarding how large companies and SMEs manage performance measure processes.

In this paper we examine the evolution of the literature and the strengths and weaknesses of the models developed for large and small companied. The evolution of the literature is discussed and a research agenda is proposed. 


\section{Literature Review}

In this section, a literature review of the PMM topic is proposed from different perspectives. First, a citation analysis is carried out for analyzing macroscopically the PMM literature. Within this analysis, number of papers, leading journals and most cited authors are some of the results. Further, PMM models founded in literature both for large and small companies are analyzed and their strengths and weaknesses are highlighted.

\subsection{Citation Analysis}

In order to examine macroscopically the literature, a citation/co-citation analysis of research on performance measurement and management is proposed by following the methodology of Neely [11]. As a consequence of that, this section can be considered an update of Neely's work.

Nowadays, recent advances in information technology and online data storage have significantly eased the process of citation/co-citation analysis. The dataset used in this paper was constructed using the ISI Web of Knowledge database. Every publication that contained the words "performance measurement" in its title, keywords or abstract was identified and consequently downloaded. This hunt identified 6,618 papers published in 546 different journals. The earliest paper included in the dataset was published in 1970 and the most recent in 2008 (91 per cent of publications included in the dataset have been published since January 1991).

The data were downloaded and analyzed using the Sitkis software [12]. Before starting the analysis process, the database generated has been substantially reviewed. Particularly, every record that related to the 20 most cited authors was reviewed and confirmed (the top 5 per cent of citations) and the title of every journal in the dataset was verified. Errors identified in the dataset were corrected in line with current best practice for bibliometric analysis [12].

The 6,618 papers included in the dataset provide some 115,547 citations, covering 88,959 works and drawing on 22,091 different lead authors. The most frequently cited authors (see Figure 1) were: R.S. Kaplan (552 citations), Abraham Charnes (271 citations), Andy Neely (249 citations), Rajiv Banker (226 citations).

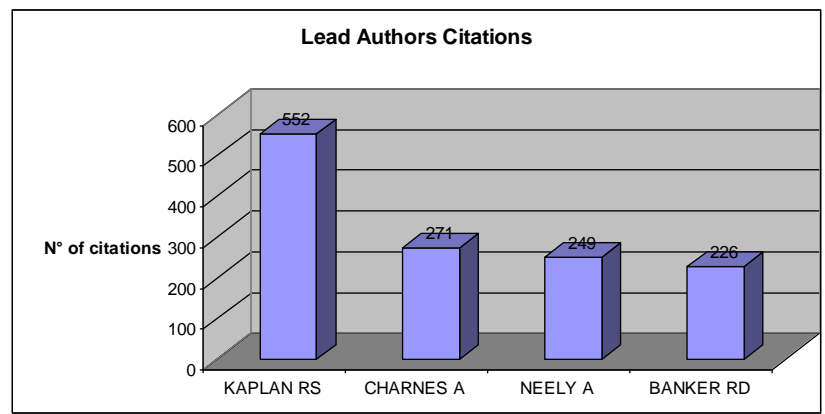

Figure 1: Lead Authors Citations

The four lead authors identified have somewhat different disciplinary backgrounds - accounting (Kaplan), operations management (Neely), accounting/operations research and information systems (Banker) and mathematics/operations research (Charnes).

The spread of journals from which citations appeared is interesting. In total, the citations were drawn from 33,971 different journals. The most frequently cited journals were the International Journal of Operation \& Production Management (943 citations), Management Science Journal (973 citations), European Journal of Operations and Research (728 citations), Strategic Management Journal (874 citations), Harvard Business Review (652 citations).

\subsection{PMM: Analysis of Citations of Data}

At a more meticulous level, it is possible to explore the frequency of citations for individual pieces of work. Once again the pattern of citations is different, further supporting the suggestion that the field of performance measurement is immature with little consensus. Only 10 works are cited more than 30 times (Table 1).

The most outstanding remark about the data included in Table 1 is the dominance of Bob Kaplan and David Norton and the Balanced Scorecard. Given that research data suggest that between 30 and 60 per cent of firms have adopted the balanced scorecard [11], this dominance is not surprising, but it is interesting, since the relative little certainty of BSC positive impact on management. At a more detailed level of analysis it is possible to review the frequency of citations over time. Figure 2 presents this for the 10 most frequently cited works.

What is remarkable to note about the data in Figure 2 is the relative stability of citations for the most frequently cited papers in terms of their continuing appearance in the citation rankings. This position contrasts with a more general analysis of the 
production and operations management (P/OM) research literature [13].

Finally, Figure 3 presents the number of citations per year while Figure 4 the number of published items per year. From such figures it is possible to remark that even if the field is relatively young and the literature appear to be yet immature, the situation is speedily evolving.

\section{Discussion of PMM Systems' Evolution - Large Companies}

In this section, the models presented in Table 2 are discussed. The main goal of such models and frameworks is to support management by helping them to measure business performance, analyze and improve business operational efficiency through better decision-making processes. Key elements for successful decision-making are well described by Vlahovic [14]. Most of the models reviewed have gone through some empirical testing and some have only theoretical developments [15].

In the 1980s, the EVA and the ABC models came as a result of observed deficiencies in the traditional accounting systems. The SMART model, developed in 1988, represents an important change in performance measurement literature, paying attention for the first time in linking strategy to operations, using external and internal measures of performance and modelling the company as an integrated system. The SPA model followed this, by introducing two important innovations that are: the concept of balanced measures and the use of nonfinancial indicators.

At the beginning of 1990s, the CVA model introduced a completely new approach, by building performance measurement exclusively from a commercial point of view. The use of a single main approach is also utilized by the BEM framework, using quality excellence as focus, and by the PDGBS, using benchmarking as approach.

In the 1990s, many PM systems and frameworks emerged trying to offer integrated solutions (RDF, BSC, SPC, IPMS, CBS, IPMF and BEM) or just specific methodologies to fix certain issues (PMQ, ROQ, CPMF and CPMS). This was followed by the balanced scorecard (BSC) model that encompassed several features such as financial and non-financial to bring out composite measures of performance. The BSC has received much attention in the last fifteen years and it has been applied to several industries successfully. The models and frameworks developed recently possess characteristics of linking strategy to operations, offering balanced set of measures (both financial and non-financial), attempting to create quantitative relations incorporating performance indicators and addressing performance measurement as a cognitive process.

The models which emerged since 2000 represent further improvement in understanding of the process. The DPMS is notable among these frameworks, since it merges all the strengths of models previously developed, by integrating the use of IT infrastructure and a quantitative model to manage cause-effect relations of performance indicators. The PP model represents incorporation of an architectural design framework. Among the latest research, the CEVITA ${ }^{\mathrm{TM}}$ and the UCDF widen the boundaries of PMM, by paying attention to the growing value of intangible assets and the importance of managing unused capacities. Given the growing importance of managing fixed cost capacities, UCDF is an important step in the literature.

A basic analysis of the works reviewed permits to distinguish which are "integrated frameworks for PMM", which are "models to face specific issues in PMM" and which are "other relevant models for PMM system design". A classification of the models reviewed based on these criteria is provided in Figure 5.

The proposed classification highlights a certain maturity of PMM literature related to large companies, and it evidences a ten of models that are considered appropriate for managing PMM initiatives since based on an integrated approach to the issue.

\section{Discussion of PMM Systems' Evolution - SMEs}

In this section, the models presented in Table 3 are discussed. First of all, it is important to highlight the immaturity of the literature in comparison of that one for large companies. However it is evident a time delay of this research field: first PMM models for large companies come from the 1980s, while first researches related to SME PMM appear just in the half of 1990s. Of course, in this period, SMEs have basically lied in financial performance measures used in large companies such as ROI, ROE, ROCE and their derivates.

At the beginning of $2000 \mathrm{~s}$, the research on performance measurement in relation to SMEs takes two directions: the first and main one is the application/adaptation of the models developed for large companies, the second one, is the development of specific models for SMEs. 
By following the first way, it is possible to find cases of implementation of the well-known BSC, application of quality models like the BEM and application of the ABC. By the other hand, it was possible to find in the literature just three frameworks proposing an integrated approach to performance measurement. It is also important to remark that such models do not demonstrate the right characteristics for moving from performance measurement to performance measurement and management. It is also interesting to highlight the fact that similarly to large companies PMM literature, the development of integrated frameworks seems to have been arrested in 20012002 , in favor of research on more specific issues. While this phenomenon can maybe be understood in large companies' research, since it happens after 10 years of research evolution and a ten of models developed, it is surely incomprehensible in SMEs research. Equally, it is difficult to justify the large research through surveys and case studies carried out in the last ten years which attempts to verify and motivate this yet immature knowledge.

Similarly to paragraph 3 , a basic analysis of the works reviewed permits to distinguish which are "integrated frameworks for SME PMM", which are "models to face specific issues in SME PMM", which are "the application/adaptation of large companies PMM models" and which are "interesting researches for PMM system design in SMEs". A classification of the models reviewed based on these criteria is provided in Figure 6.

\section{PMM Research - What is Next}

Nowadays, academics are paying great attention to identify logics and drivers allowing enterprises to be effectively managed through the measurement of their performances. Another fundamental objective consists in identifying the way data and information can be transformed in value-making activities. It means that researchers, engaged in the PMM field, are investigating how companies can achieve objectives they plan to achieve through the measurement of their performances [16].

In order to improve the effectiveness of PMM models two kind of interventions have to be performed. First of all, the needed conditions for a correct and effective utilization of PMM models have to be created within companies. It, mainly, means providing enterprises with IT tools needed to extract, collect and elaborate data characterizing their business. This intervention represents an essential task for the majority of SMEs. Furthermore, also the logic of PMM models needs to be modified. Particularly, they should allow companies to identify relationships between processes their business is based on [17]. In such a way they can really contribute to fulfil the "knowing-doing" gap [18]. The "knowing-doing" gap expresses the difficulty of companies in effectively translating information coming from the measurement of processes into effective tasks. This difficulty is not caused by the impossibility of models in finding a right set of KPIs for monitoring enterprise's processes. Instead, it depends on the scarce comprehension of cause-effect relationships the value of each indicator is based on. Success Maps [19] and Strategy Maps [20] approaches, and the logic the MSDD model [21] is based on have contributed to define guidelines to effectively deal with "knowing-doing" gap-related troubles. In spite of that, the attempt to comprehend the value-chain cause-effect relationships for different typologies of companies and the implementation of this model within operational IT tools, can even be considered a challenge in the PMM research field.

An additional lack to previous one opens while thinking to SMEs. In this context in fact, the situation related to PMM models adoption appears quite different, since characterized by a minimum percentage of adoption. Motivations related to unsuccessful utilization of PMM models within SMEs can be ascribed both to intrinsic factors of this typology of companies both to PMM models unsuitability. The first aspect, is due to a cultural lack which afflicts transversely SMEs: by management side, there is in fact benefits incomprehension and costs fear; while by operators' side, there is rejection for a system which is perceived as intrusive. Therefore the need of structural actions aimed to create early conditions for PMM models implementation. Furthermore, the need of a PMM models revision, so as to effectively face characteristics problems of SMEs. Particularly, these initiatives have to be carried out in attention of implementation costs.

The huge difference existing between big and small company problems explains the reasons whereby PMM models developed for big companies cannot be adapted to SMEs, therefore the need of specific research.

Figure 7 highlights therefore the areas of future research.

\section{Conclusions}

This paper carried out a literature review highlighting the state of the art of PMM research applied to Large and Small and Medium 
Enterprises. The main PMM models and frameworks developed in the last twenty years have been discussed so as to depict the evolution of the research field. The state of art which emerged appears completely different for large and small companies. The literature related to large companies appears in fact quite mature, and future research address to solve the difficulty of companies in effectively translating information coming from the measurement of processes into effective tasks. This issue is well-known as the "knowing-doing" gap and can be referred also as the difficulty of moving from performance measurement to performance measurement and management.

In the SME context the situation is completely different. The literature appears immature and the models indentified often fail while implemented. Future research will focus on the creation of early conditions for PMM models implementation and on the development of specific PMM models tailored on SME characteristics and needs. 


\section{APPENDIX A - FIGURES}

Figure 2 - Changing Patterns of Citation Frequency

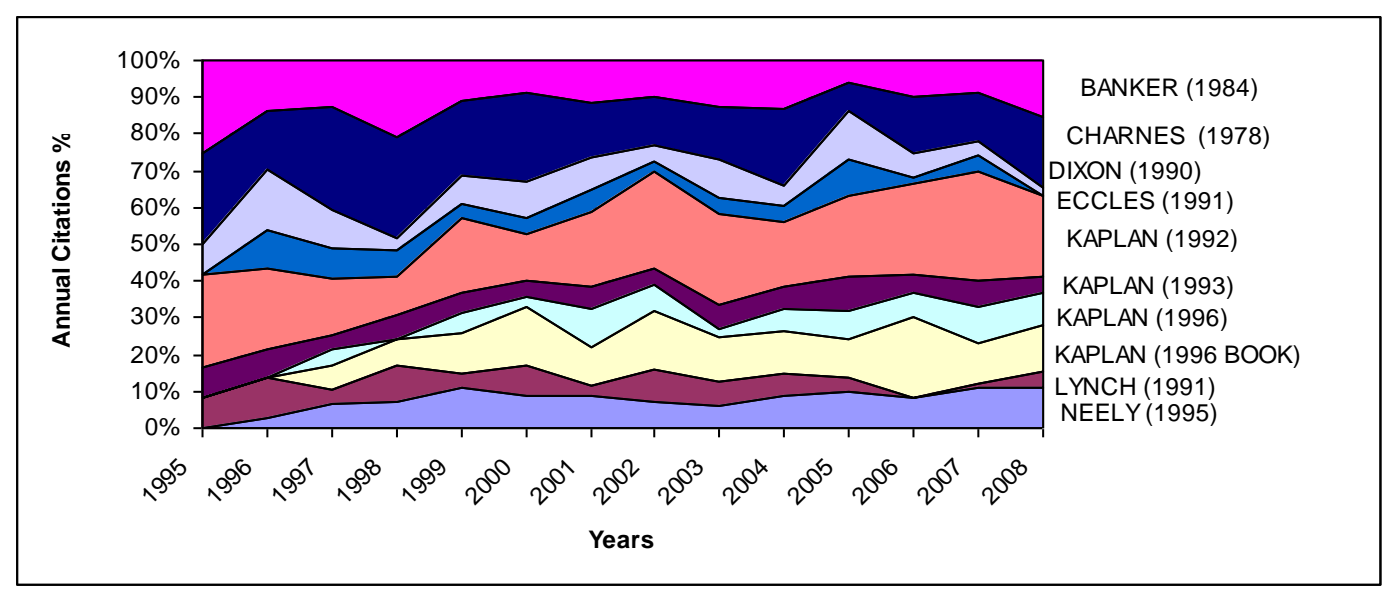

Figure 3 - Citations per year

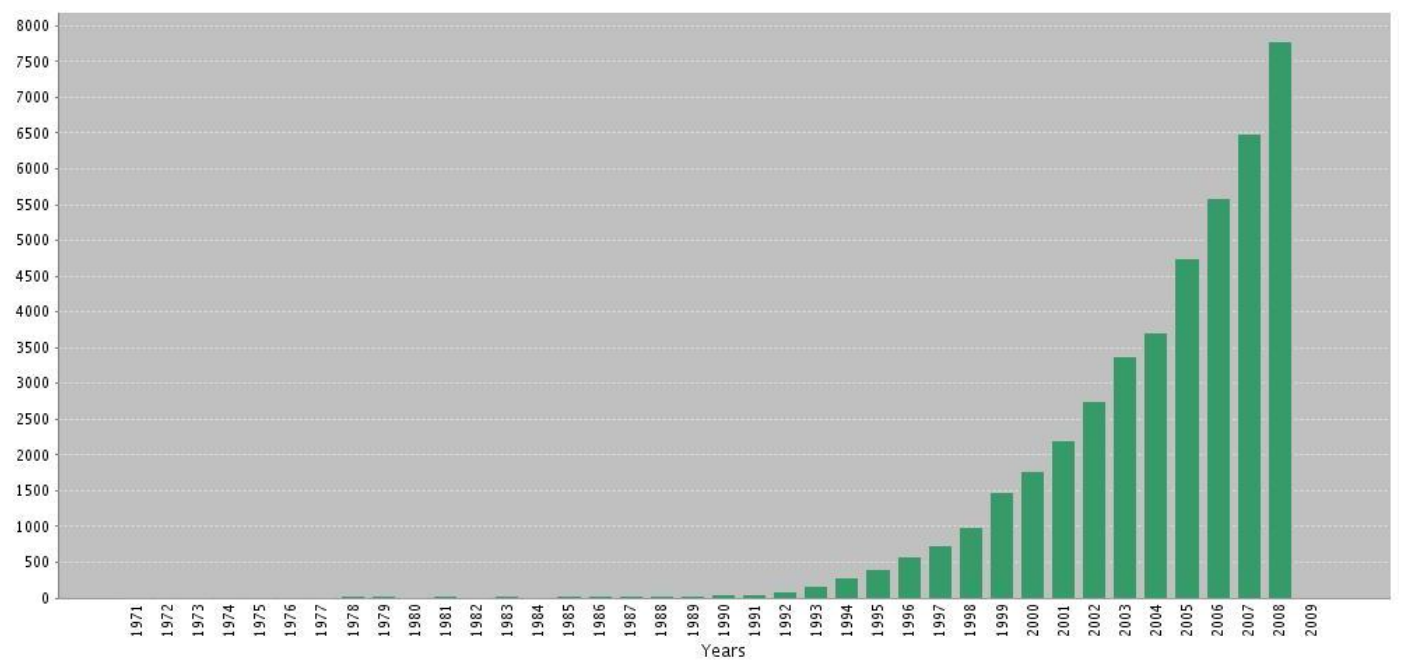

Figure 4 - Published Items per Year

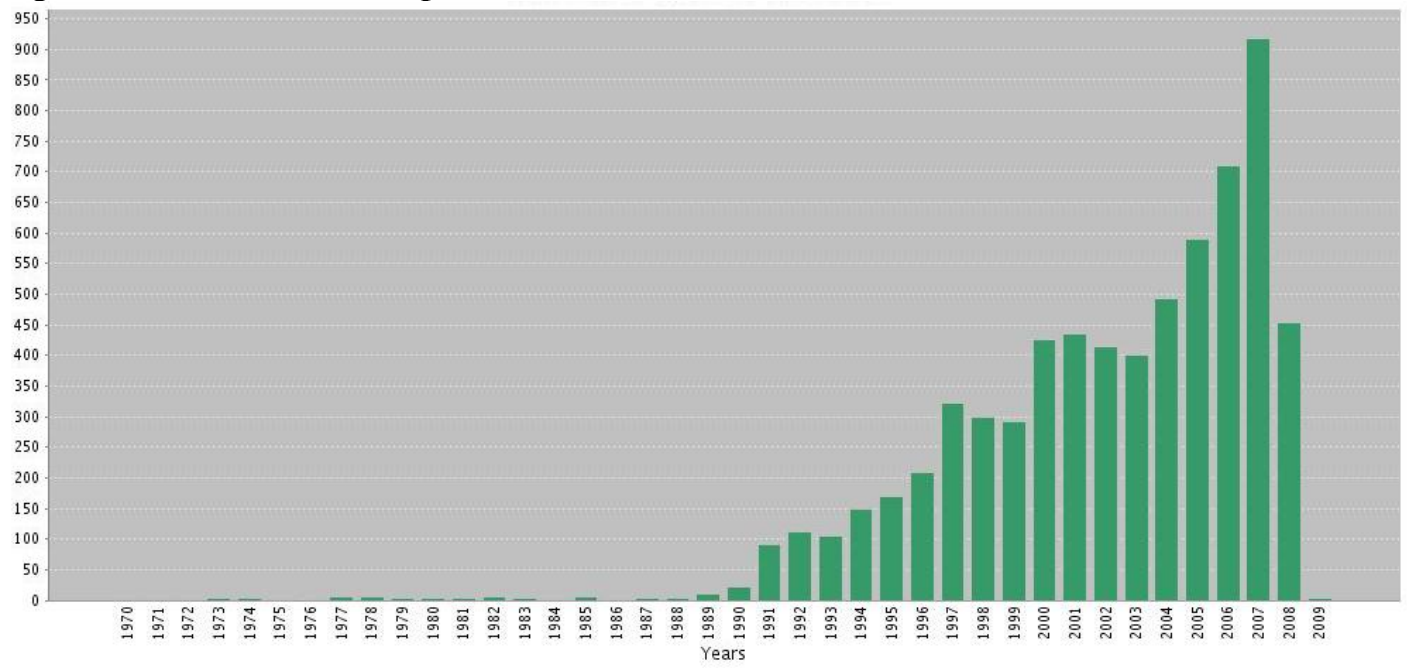


Figure 5 - Classification of Models and Frameworks for Large Companies

\author{
Integrated Frameworks for PMM \\ 1988 The Strategic Measurement Analysis and Reporting Technique \\ 1989 The Supportive Performance Measures \\ 1991 The Results and Determinants Framework \\ 1992 The Balanced Scorecard \\ 1994 The Service Profit Chain \\ 1997 The Integrated Performance Measurement System \\ 1998 The Comparative Business Scorecard \\ 1998 The Integrated Performance Measurement Framework \\ 2000 The Dynamic Performance Measurement System \\ 2001 The Performance Prism \\ Models to Face Specific Issues in PMM \\ 1980 The Economic Value Added Model \\ 1990 The Performance Measurement Questionnaire \\ 1995 The Return on Quality \\ 1996 The Cambridge Performance Measurement Framework \\ 1996 The Consistent Performance Measurement System \\ 2001 The Action Profit Linkage Model \\ 2004 The Performance Planning Value Chain \\ 2004 The Capability Economic Value of Intangible and Tangible Assets Model \\ 2006 The Performance, Development and Growth Benchmarking System \\ 2007 The Unused Capacity Decomposition Framework \\ Other Relevant Models for PMM System Design \\ 1988 The Activity-based Costing \\ 1990 The Customer Value Analysis \\ 1999 The European Foundation for Quality Management Model \\ 2001 The Manufacturing System Design Decomposition
}

Figure 6 - Classification of Models and Frameworks for SMEs

Integrated Frameworks for SME PMM

2000 OPM ${ }^{\circledR}$ : a system for organizational performance measurement

2001 Effective performance measurement in SMEs

2002 Dynamic Integrated Performance Measurement System

Models to Face Specific Issues in SME BPM

1998 Customer Orientation and Performance

2000 Computer-Based Performance Measurement in SMEs

2007 A BPI framework and PAM for SMEs

Application/Adaptation of Large Companies PMM Models 1995 Model for quality-based performances

1997 BSC Application to SMEs

1999 Activity Based Costing in SMEs

2000 Quality Models in an SME context

2000 Performance measurements in the implementation of CIM in SMEs

2004 A strategic planning model for SMEs based on the BSC

2007 BSC Implementation in a not for profit SME

Interesting Researches for PMM System Design in SMEs

2000 Performance Measurement Based on SME Owner's Objectives

2001 Indicators for performance measurement in SMEs

2001 Theory and practice in SME performance measurement systems

2005 Practice of performance measurement

2008 A Performance Measurement Model Based on the Grounded Theory Approach 
Figure 7 - Areas of Future Research

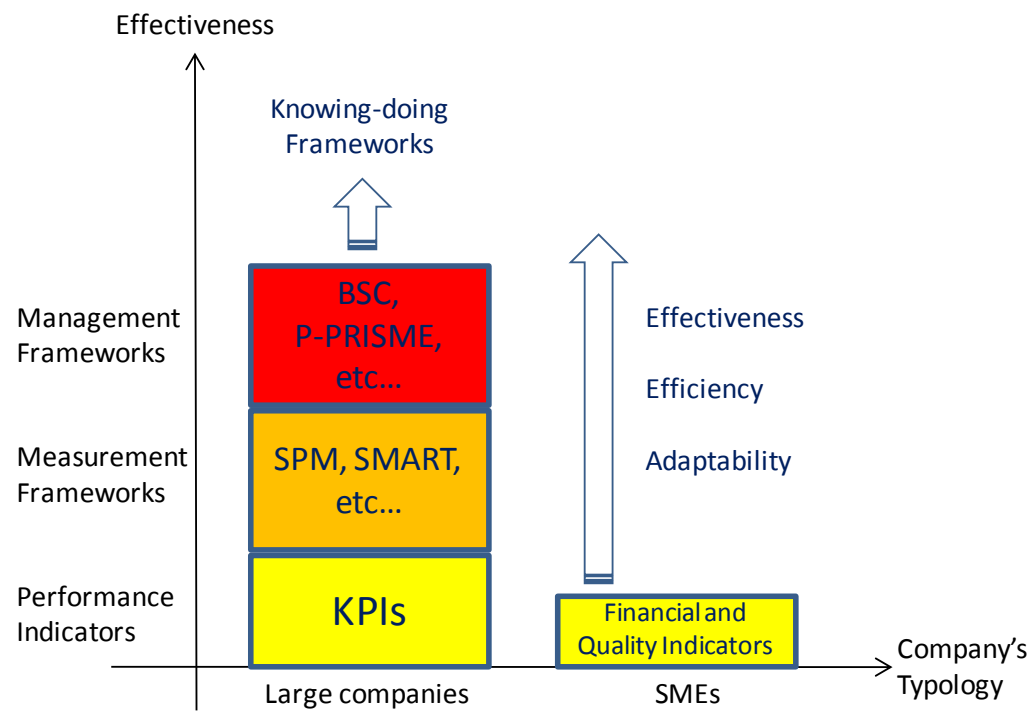

\section{APPENDIX B - TABLES}

Table 1 - Most Frequently Cited Performance Measurement Works

\begin{tabular}{|c|c|c|c|}
\hline Author & Journal & Year & Citations \\
\hline $\begin{array}{l}\text { Kaplan, R.S. and Norton, } \\
\text { D.P. }\end{array}$ & $\begin{array}{l}\text { The balanced scorecard: measures that drive } \\
\text { performance, Harvard Business Review, January- } \\
\text { February, pp. 71-79 }\end{array}$ & 1992 & 168 \\
\hline $\begin{array}{l}\text { Kaplan, R.S. and Norton, } \\
\text { D.P. }\end{array}$ & $\begin{array}{l}\text { The Balanced Scorecard: Translating Strategy Into } \\
\text { Action, Harvard Business School Press, Boston, MA }\end{array}$ & 1996 & 92 \\
\hline $\begin{array}{l}\text { Charnes, A.; Cooper, } \\
\text { W.W. } \\
\text { and Rhodes, E. }\end{array}$ & $\begin{array}{l}\text { Measuring efficiency of decision-making units, } \\
\text { European Journal of Operations Research, 2, 6, pp. } \\
429-444\end{array}$ & 1978 & 135 \\
\hline $\begin{array}{l}\text { Dixon, J.; Nanni, A., } \\
\text { and Vollmann, T. }\end{array}$ & $\begin{array}{l}\text { The New Performance Challenge, Business One, } \\
\text { Irwin, Burr Ridge, IL }\end{array}$ & 1990 & 63 \\
\hline $\begin{array}{l}\text { Neely, A.D., Gregory, M. } \\
\text { and Platts, K. }\end{array}$ & $\begin{array}{l}\text { Performance measurement system design: a literature } \\
\text { review and research agenda, International Journal of } \\
\text { Operations \& Production Management, 15, 4, pp. 80- } \\
116\end{array}$ & 1992 & 67 \\
\hline Eccles, R.G. & $\begin{array}{l}\text { The performance measurement manifesto, Harvard } \\
\text { Business Review, January-February, pp. 131-137 }\end{array}$ & 1991 & 41 \\
\hline $\begin{array}{l}\text { Lynch R.L. and Cross, } \\
\text { K.F. }\end{array}$ & Measure Up!, Blackwell Publishers, Cambridge, MA & 1991 & 40 \\
\hline $\begin{array}{l}\text { Kaplan, R.S. and Norton, } \\
\text { D.P. }\end{array}$ & $\begin{array}{l}\text { Putting the balanced scorecard to work, Harvard } \\
\text { Business Review, September-October, pp. 134-147 }\end{array}$ & 1993 & 48 \\
\hline $\begin{array}{l}\text { Banker, R.D.; Charnes, } \\
\text { A. } \\
\text { and Cooper, W.W. }\end{array}$ & $\begin{array}{l}\text { Some models for estimating technical and scale } \\
\text { inefficiencies in data envelopment analysis, } \\
\text { Management Science, 30, 9, pp. 1078-1092 }\end{array}$ & 1984 & 88 \\
\hline Kaplan, R.S. & $\begin{array}{l}\text { Using the balanced scorecard as a strategic } \\
\text { management system, Harvard Business Review, } 74,1 \text {, } \\
\text { pp. } 75-85\end{array}$ & 1996 & 48 \\
\hline
\end{tabular}


Table 2 - Large Companies, Models and Frameworks Analyzed

\begin{tabular}{lc}
\hline Name of the Model/Framework & Period of Introduction \\
\hline The ROI, ROE, ROCE and derivates & Before $80 s$ \\
The Economic Value Added Model (EVA) & 1980 \\
The Activity Based Costing (ABC) - The Activity Based Management (ABM) & 1988 \\
The Strategic Measurement Analysis and Reporting Technique (SMART) & 1988 \\
The Supportive Performance Measures (SPA) & 1989 \\
The Customer Value Analysis (CVA) & 1990 \\
The Performance Measurement Questionnaire (PMQ) & 1990 \\
The Results and Determinants Framework (RDF) & 1991 \\
The Balanced Scorecard (BSC) & 1992 \\
The Service-Profit Chain (SPC) & 1994 \\
The Return on Quality Approach (ROQ) & 1995 \\
The Cambridge Performance Measurement Framework (CPMF) & 1996 \\
The Consistent Performance Measurement System (CPMS) & 1996 \\
The Integrated Performance Measurement System (IPMS) & 1997 \\
The Comparative Business Scorecard (CBS) & 1998 \\
The Integrated Performance Measurement Framework (IPMF) & 1998 \\
The Business Excellence Model (BEM) & 1999 \\
The Dynamic Performance Measurement System (DPMS) & 2000 \\
The Action-Profit Linkage Model (APL) & 2001 \\
The Manufacturing System Design Decomposition (MSDD) & 2001 \\
The Performance Prism (PP) & 2001 \\
The Performance Planning Value Chain (PPVC) & 2004 \\
The Capability Economic Value of Intangible and Tangible Assets Model (CEVITA & 2004 \\
The Performance, Development, Growth Benchmarking System (PDGBS) & 2006 \\
The Unused Capacity Decomposition Framework (UCDF) & 2007 \\
\hline
\end{tabular}

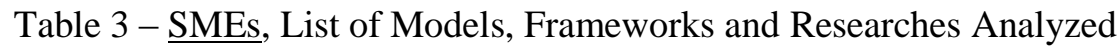

\begin{tabular}{lc}
\hline Name of the Model/Framework/Research & Period of Introduction \\
\hline Model for quality-based performances & 1995 \\
BSC Application to SMEs & 1997 \\
Customer Orientation and Performance & 1998 \\
Activity Based Costing in SMEs & 1999 \\
Quality Models in an SME context & 2000 \\
Computer-Based Performance Measurement in SMEs & 2000 \\
OPM® : a system for organisational performance measurement & 2000 \\
Performance measurements in the implementation of CIM in SMEs & 2000 \\
Performance Measurement Based on SME Owner's Objectives & 2000 \\
Effective performance measurement in SMEs & 2001 \\
Indicators for performance measurement in SMEs & 2001 \\
Theory and practice in SME performance measurement systems & 2001 \\
Dynamic Integrated Performance Measurement System & 2002 \\
A strategic planning model for SMEs based on the BSC & 2004 \\
Practice of performance measurement & 2005 \\
BSC Implementation in a not for profit SME & 2007 \\
A BPI framework and PAM for SMEs & 2007 \\
A Performance Measurement Model Based on the Grounded Theory Approach & 2008 \\
\hline
\end{tabular}




\section{References:}

[1] Niedrite, L., Solodovnikova, D., Treimanis, M., Niedritis, A. (2007) "Goal-Driven Design of a Data Warehouse-Based Business Process Analysis System", Proceedings of the 6th WSEAS Int. Conf. on Artificial Intelligence, Knowledge Engineering and Data Bases, Corfu Island, Greece, February 16-19, 2007

[2] Motta, G., Zanga, E., D’Agnone, P., (2006) "Process performances and process stakeholders:

a case study in the health care", Proceedings of the 7th WSEAS International Conference on Automation \& Information, Cavtat, Croatia, June 13-15, 2006 (pp48-52) [3] Milimd Kumar Sharma,Rajat Bhagwat,Govind Sharan Dangayach (2005) "Practice of performance measurement: experience from Indian SMEs", International Journal Globalisation and Small Business, vol1.no2, pp.183-213.

[4] Neely, A., Adams, C. and Kennerley, M. (2002), The Performance Prism: the Scorecard for Measuring and Managing Stakeholder Relationship, London: Prentice Hall.

[5] Kaplan, R. and Norton, D. (1996), "Using the Balanced Scorecard as a strategic management system", Harvard Business Review, Jan-Feb, 75-85.

[6] Bititci, U.S., Turner, T. and Begemann, C. (2000), "Dynamics of performance measurement systems.", International Journal of Operations and Production Management, Vol. 20, pp. 692-704.

[7] Habjan, A., Popovic, A. (2007) "Achieving Business Process Change With Improved Business Intelligence Systems: A Case Of Slovenian Company", WSEAS TRANSACTIONS on BUSINESS and ECONOMICS, Issue 7, Volume 4, July 2007

[8] Panian, Z., (2008) "How to Make Business Intelligence Actionable through Service-oriented Architectures", WSEAS TRANSACTIONS on BUSINESS and ECONOMICS, Issue 5, Volume 5, May 2008

[9] Garengo, P., Biazzo, S. and Bititci, U.S. (2005), "Performance measurement systems in SMEs: A review for a research agenda", International Journal of Management Reviews, Vol. 7 No. 1, pp. 25-47.

[10] Hudson, M., Smart, A. and Bourne, M. (2001), "Theory and practice in SME performance measurement systems", International Journal of Operations \& Production Management, Vol. 21 No. 8, pp. 1096-115.

[11]Neely, A., (2005) "The Evolution of Performance Measurement Research: Development in the last decade and a research agenda for the next", International Journal of Operations\&Production Management, Vol. 25, No.12, pp. 1264-1277

[12] Schildt, H.A. (2002), SITKIS: Software for Bibliometric Data Management and Analysis, Helsinki Institute of Strategy and International Business.

[13] Neely, A.D., Lewis, M.A., (2005) "What has 25 years of P/OM research taught us about productivity", Proceedings of the $12^{\text {th }}$ European Operations Management Association Conference, Budapest

[14] Vlahovic, N., (2008) "Discovering Tacit Knowledge in Business Decision Making", WSEAS
TRANSACTIONS on BUSINESS and ECONOMICS, Issue 3, Volume 5, March 2008

[15] Pun, K.F., White, A.S., (2005) "A performance measurement paradigm for integrating strategy formulation: a review of systems and frameworks", International Journal of Management Reviews, 7, 1, pp. 49-71

[16] Evans, J.R. (2001), "An Exploratory Study of Performance Measurement Systems and Relationship With Performance Results", Presented at the Decisions Science Institute, 32nd Annual Conference, San Francisco, pp. 1-27.

[17] Bourne M., Mills J., Wilcox M., Neely A., Platts K., (2000) "Designing, implementing and updating performance measurement systems", International Journal of Operations and Production Management, vol.20, n.7, pp.754-771.

[18] Cohen, H.B. (1998), "The Performance Paradox", The Academy of Management Executive, Vol. 12, No. 3, pp. 30-40.

[19] Neely, A., Adams, C., Kennerly M., (2002) "The performance prism", Prentice Hall.

[20] Kaplan, R.S., Norton, D.P., (2004) "Strategy Maps", Harvard Business School Publishing Corporation, Boston, MA.

[21] Cochran D.S., Arinez, J.F., Duda, J.W., Linck, J., (2001) "A Decomposition Approach for Manufacturing System Design", Journal of Manufacturing Systems, Vol. 20 , n. 6 . 